\title{
INTERPRETAÇÃO INICIAL DOS DADOS OBTIDOS NA ESCAVAÇÃO DA LAPA DO FOGÃO
}

\author{
Wagner Marin Gomes*
}

\section{Resumo}

Este texto tem por objetivo apresentar a análise inicial da distribuição espacial, em termos geoestatísticos, do material arqueológico encontrado ao longo de toda superfície escavada na área 1 da Lapa do Fogão. Para que isso seja feito de forma mais clara, apresentarei inicialmente a metodologia de escavação utilizada, em seguida quais materiais foram levados em consideração para esta análise preliminar e como os dados foram organizados, finalmente os primeiros resultados da análise utilizando o método de agrupamento chamado Grade ofMembership (GoM). Não faz parte do objetivo deste trabalho discutir correntes teóricas sobre espaço e tecnologia lítica.

Palavras-chave:Geoprocessamento, estatística, arqueologia.

\begin{abstract}
This text aims to present the initial analysis of the spatial distribution in geostatistical terms, the archaeological material found throughout the excavated surface area 1 of the Lapa stove. For this to be done more clearly, I will present the methodology originally used to dig, then what materials were considered for this preliminary analysis and how the data were organized, finally the first results of the analysis using the clustering method called Grid of Membership (GoM). Not part of the objective of this study discuss theoretical perspectives on space and lithic technology.
\end{abstract}

Keywords:GIS, statistics, archeology.

"Universidade Federal de Minas Gerais - UFMG. wagnerclimber@gmail.com 


\section{INTRODUÇÃO}

Este texto tem por objetivo apresentar aanálise inicial da distribuição espacial, em termos geoestatísticos, do material arqueológico encontrado ao longo de toda superfície escavada na área 1 da Lapa do Fogão. Para que isso seja feito de forma mais clara, apresentarei inicialmente a metodologia de escavação utilizada, em seguida quais materiais foram levados em consideração para esta análise preliminar e como os dados foram organizados, finalmente os primeiros resultados da análise utilizando o método de agrupamento chamado Grade ofMembership (GoM). Não faz parte do objetivo deste trabalho discutir correntes teóricas sobre espaço e tecnologia lítica.

\section{METODOLOGIA DE ESCAVAÇÃO}

A questão norteadora da dissertação quepretendo desenvolver a partir dotrabalho de resgate do material arqueológico da Lapa do Fogão e sua análise é: Através da variabilidade artefatual e sua distribuição espacial é possível atribuir uma intencionalidade do uso do espaço?

Baseado nesta questão é que a metodologiautilizada para escavação da Lapa do Fogão teve como objetivo manter o controle estratigráfico e o registro tridimensional do material escavado, sendo assim adotou-se o sistema de escavação por níveis artificiais de $5 \mathrm{~cm}$ e levando em consideração a variação estratigráfica (possíveis níveis de ocupação, ou melhor, de interação antrópica) a qual foi registrada ao longo da escavação através das plantas baixas e dos perfis ao final de todo o trabalho de escavação onde foi possível ter uma fissão geral dos perfis de toda a superfície. Esta metodologia foi desenvolvida por Kipnis(2003) para o estudo dos sítios sob abrigo escavados pelo laboratório de estudos evolutivo/USP na região de Lagoa Santa. Adotar esta metodologia também possibilitará a comparação do material analisado com outros estudos.

Toda a área interna da lapa foi dividida em unidades de escavação de 1 x $1 \mathrm{~m}$; o material arqueológico encontrado foi registrado obtendo um endereço x, y e z a partir de um ponto aleatório denominado Datum. A partir deste ponto, foi feita a topografia de todo o abrigo.

As características do sedimento ao longo dos níveis artificiais de $5 \mathrm{~cm}$ escavação também foram registradas e denominadas fácies. Essas fácies atravessam tanto horizontal 
como verticalmente os níveis escavados e teve por objetivo analisar possíveis testemunhos das atividades antrópicas deixadas no sedimento do abrigo.

\section{TRATAMENTO DOS DADOS}

Após a escavação, todos os materiaisplotados foram organizados em uma tabela do Excel por quadra, nível e fácies, assim, foi possível obter a quantidade de material para cada quadra em cada nível, sem levar em consideração o material encontrado em peneira. Este será tradado e adicionado aos dados ao longo do desenvolvimento dos estudos.

Para o tratamento inicial dos foi feita aanálise crítica dos dados onde foram retiradas variáveis não utilizadas e incialmente feita uma frequência simples o que possibilitou ter um panorama geral das caraterísticas mais representativas da amostra e finalmente realizou-se as primeiras experimentações com o método de agrupamento GoM onde separou-se a amostra em 4 grupos.

Através destas análises, foi possívelperceber características do material escavado que apontou caminhos para direcionar os estudos da Lapa para justificar o atual estado deste material.

A figura 1 mostra toda a superfícieescavada da área 1 e a divisão das unidades de escavação.

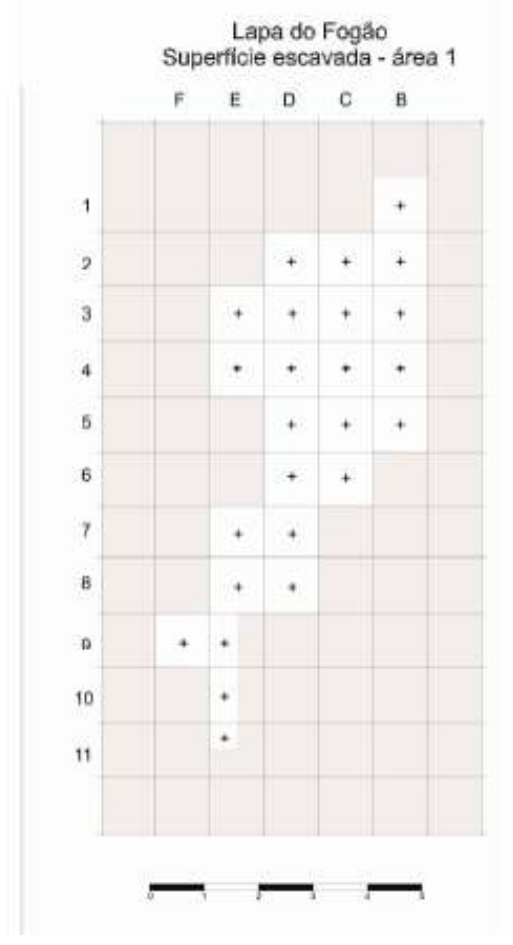


Figura 1: Superfície escavada na área 1 da Lapa do Fogão e o ponto central de cada quadra.

A tabela 1 abaixo, mostra a distribuição daquantidade de material por quadra, pornível.

\begin{tabular}{|c|c|c|c|c|c|c|c|c|c|c|c|c|c|c|c|c|c|c|c|c|c|c|c|}
\hline \multirow{3}{*}{ Quadra } & \multirow[b]{3}{*}{\begin{tabular}{|l|}
$\mathbf{y}$ \\
\end{tabular}} & \multirow[b]{3}{*}{$\mathbf{x}$} & \multicolumn{21}{|c|}{ Quantidade de material coletado - Z } \\
\hline & & & \multicolumn{21}{|c|}{ Níveis } \\
\hline & & & Sup.* & 1 & 2 & 3 & 4 & 5 & 6 & 7 & 8 & 9 & 10 & 11 & 12 & 13 & 14 & 15 & \begin{tabular}{|l|}
16 \\
\end{tabular} & 17 & 18 & 19 & 20 \\
\hline B1 & 5,5 & 11,5 & 13 & 3 & 4 & 8 & 0 & 6 & 7 & 7 & 2 & 0 & 0 & 0 & 0 & 0 & 0 & 0 & 0 & 0 & 0 & 0 & 0 \\
\hline B2 & 5.5 & 10.5 & 7 & 4 & 3 & 0 & 0 & 13 & 18 & 15 & 22 & 18 & 19 & 0 & 6 & 1 & 1 & 2 & 0 & 0 & 0 & 0 & 0 \\
\hline B3 & 5,5 & 9.5 & 0 & 0 & 0 & 0 & 0 & 0 & 0 & 0 & 0 & 0 & 0 & 0 & 0 & 0 & 0 & 0 & 0 & 0 & 0 & 0 & 0 \\
\hline B4 & 5,5 & 8,5 & 0 & 0 & 18 & 12 & 2 & 24 & 5 & 3 & 1 & 0 & 0 & 0 & 0 & 0 & 0 & 0 & 0 & 0 & 0 & 0 & 0 \\
\hline B5 & 5,5 & 7,5 & 0 & 0 & 1 & 5 & 5 & 0 & 6 & 10 & 9 & 1 & 2 & 0 & 0 & 0 & 0 & 0 & 0 & 0 & 0 & 0 & 0 \\
\hline $\mathrm{C2}$ & 4,5 & 10.5 & 0 & 1 & 7 & 31 & 5 & 89 & 50 & 34 & 19 & 3 & 3 & 0 & 1 & 0 & 0 & 0 & 0 & 0 & 0 & 0 & 0 \\
\hline $\mathrm{C3}$ & 4,5 & 9.5 & 0 & 8 & 8 & 17 & 0 & 90 & 27 & 12 & 10 & 4 & 1 & 0 & 3 & 0 & 0 & 0 & 0 & 0 & 0 & 0 & 0 \\
\hline $\mathrm{C4}$ & 4,5 & 8,5 & 0 & 5 & 21 & 18 & 0 & 44 & 17 & 27 & 12 & 3 & 0 & 0 & 3 & 0 & 0 & 0 & 0 & 0 & 0 & 0 & 0 \\
\hline C5 & 4,5 & 7,5 & 0 & 5 & 9 & 15 & 39 & 13 & 5 & 8 & 10 & 4 & 0 & 0 & 1 & 0 & 0 & 0 & 0 & 0 & 0 & 0 & 0 \\
\hline C6 & 4,5 & 6.5 & 1 & 0 & 8 & 30 & \begin{tabular}{l|l}
0 \\
\end{tabular} & 12 & 9 & 30 & 36 & 5 & 0 & 0 & 0 & 0 & 0 & 0 & 0 & 0 & 0 & 0 & 0 \\
\hline D2 & 3,5 & 10,5 & 0 & 5 & 2 & 3 & 6 & 0 & 1 & 2 & 1 & 0 & 0 & 0 & 0 & 0 & 0 & 0 & 0 & 0 & 0 & 0 & 0 \\
\hline D3 & 3,5 & 9,5 & 0 & 26 & 15 & 33 & 10 & 0 & 7 & 0 & 0 & 0 & 0 & 0 & 0 & 0 & 0 & 0 & 0 & 0 & 0 & 0 & 0 \\
\hline D4 & 3.5 & 8.5 & 0 & 20 & 24 & \begin{tabular}{|l|}
24 \\
\end{tabular} & \begin{tabular}{l|l}
0 \\
\end{tabular} & \begin{tabular}{|l|}
39 \\
\end{tabular} & 34 & 3 & 3 & 3 & 0 & 0 & 0 & 0 & 0 & 0 & 0 & 0 & 0 & 0 & 0 \\
\hline D5 & 3,5 & 7,5 & 3 & 6 & 16 & 0 & 51 & 56 & 3 & 6 & 14 & 0 & 0 & 0 & 0 & 0 & 0 & 0 & 0 & 0 & 0 & 0 & 0 \\
\hline D6 & 3,5 & 6,5 & 2 & 4 & 0 & 10 & 33 & \begin{tabular}{l|l|}
39 & \\
\end{tabular} & 11 & 48 & 137 & 54 & 17 & 0 & 0 & 1 & 0 & 0 & 0 & 0 & 0 & 0 & 0 \\
\hline D7 & 3,5 & 5,5 & 0 & 3 & 9 & 2 & 0 & 20 & 63 & 193 & \begin{tabular}{|l|}
36 \\
\end{tabular} & \begin{tabular}{|l|}
49 \\
\end{tabular} & 56 & 0 & 4 & 0 & 0 & 0 & 0 & 0 & 0 & 0 & 0 \\
\hline D8 & $\begin{array}{l}3.5 \\
\end{array}$ & 4.5 & 0 & 2 & 3 & 8 & 2 & 5 & 1 & 8 & \begin{tabular}{|l|}
29 \\
\end{tabular} & \begin{tabular}{|l|}
19 \\
\end{tabular} & 2 & 0 & 36 & 36 & 0 & 0 & 0 & 0 & 0 & 0 & 0 \\
\hline E10 & 2.25 & 2,5 & 0 & 0 & 0 & 0 & 0 & 1 & 0 & 0 & 8 & 2 & 0 & 0 & 0 & 0 & 0 & 0 & 0 & 0 & 0 & 0 & 0 \\
\hline E11 & 2.25 & 1,75 & 0 & 0 & 0 & \begin{tabular}{|l|} 
\\
\end{tabular} & 0 & 0 & 0 & 0 & 2 & 0 & 0 & 0 & 0 & 0 & 0 & 0 & 0 & 0 & 0 & 0 & 0 \\
\hline E3 & 2,5 & 9,5 & 0 & 0 & 0 & \begin{tabular}{|l|}
6 \\
\end{tabular} & 0 & 0 & $\begin{array}{ll}0 \\
\end{array}$ & 0 & 0 & 0 & 0 & 0 & 0 & 0 & 0 & 0 & 0 & 0 & 0 & 0 & 0 \\
\hline E4 & 2.5 & 8.5 & 0 & 0 & 0 & 0 & 0 & 0 & 0 & 0 & 0 & 0 & 0 & 0 & 0 & 0 & 0 & 0 & 0 & 0 & 0 & 0 & 0 \\
\hline E7 & 2,5 & 5,5 & 0 & 1 & \begin{tabular}{|l|}
10 \\
\end{tabular} & 26 & 2 & 14 & 26 & 18 & 5 & 9 & 4 & 0 & 28 & 2 & 3 & 0 & 2 & 0 & 0 & 0 & 0 \\
\hline E8 & 2,5 & 4,5 & 0 & 1 & 0 & $\begin{array}{ll} \\
\end{array}$ & 0 & 0 & 2 & 3 & 2 & 3 & 0 & 0 & 6 & 4 & 7 & 12 & 2 & 6 & \begin{tabular}{|l|}
29 \\
\end{tabular} & 13 & 6 \\
\hline E9 & 2,25 & 3,5 & 0 & 0 & 0 & 0 & 0 & 0 & 0 & 0 & 0 & 0 & 0 & 0 & 0 & 0 & 1 & 0 & 0 & 1 & 2 & 0 & 6 \\
\hline F9 & 1.5 & 3.5 & 0 & 0 & 0 & 0 & 0 & \begin{tabular}{l|l} 
& \\
\end{tabular} & \begin{tabular}{|l|}
0 \\
\end{tabular} & 0 & 0 & 0 & 0 & 0 & 0 & 0 & 0 & 0 & 0 & 0 & 0 & \begin{tabular}{l|l}
0 \\
\end{tabular} & 7 \\
\hline \multicolumn{24}{|c|}{ * Superficie } \\
\hline
\end{tabular}

\section{ANÁLISE DOS RESULTADOS}

O Material lítico escavado foi analisadosegundo uma tabela de atributos que contemplam características físicas do material como Matéria prima, condição, intrusão, cor, transparência e, características tecnológicas, ou seja, aspectos relacionados a manufatura e/ou manutenção de instrumentos em pedra lascada como Integridade, Percussão, talão, bulbo, clivagem, suporte, local do córtex, perfil do eixo e relação entre eixos.

Como este trabalho é uma nota preliminar daanálise não me aterei em explicar estas variáveis mas todas são pertinentes para a tendência atual de estudo das industrias líticas 
pré-históricas que se preocupa em perceber tipos tecnológicos que possibilitem encaixar o material ao longo de toda uma cadeia operatória apresentada pela primeira vez na década de 60 do Sec XX por André LeroiGourham e trata da vida de um artefato desde a obtenção da matéria prima, passando pela manufatura, manutenção e finalmente o descarte deste instrumento. É a partir do seuabandono que segundo Schiffer (1972) oartefato entra em contexto arqueológico e começa a sofrer os processos de transformação do registro arqueológico até o momento em que este foi encontrado.

Depois da análise crítica dos dados gerou-seuma frequência simples de todos os atributos(tabela 2), no software SPSS 20 os atributos que se demonstraram mais expressivos para a caracterização do material foram a matéria prima (mp), a condição, cor e percussão. Através do GoM foi possível perceber como os outros atributos se vinculam aos acima citados.

Voltando a frequência simples, das 2219 observações, cerca de $95 \%$ da amostra é composta por quartzo, $62 \%$ encontra-se quebrado, $65 \%$ possui cor branca, $52,7 \%$ transparência leitosa e 54,9\% das lascas foram originadas de percussão unipolar, ou seja, as lascas foram geradas através da percussão em somente um local ou plano de percussão. Oque já mostra que a grande maioria da indústria lítica da Lapa do fogão foi desenvolvida em

quartzo leitoso provenientes de veios muito comuns na região da Serra do Espinhaço, este material devido a sua gênese e inserção guarda características como a presença de clivagens o que poderia gerar lascas "incompletas" que foram classificadas como fragmentadas.

A análise dos dados a partir do GoM foi realizada com o software GoM3, executável

em ambiente DOS, um dos programas mais comumente usados.É gratuito e se encontra disponívelnaInternet(http://www.stat.unipg.it/stat/statlib/DOS/general/). Segundo CAETANO 2009, O algoritmo utilizados o de Woodbury e Clive (1974) e, sobeste algoritmo, os parâmetros gike $\lambda$ kjlsão interativamente estimados. Ainda segundo CAETANO 2009, o método se apresenta atrativo, por gerar dois conjuntos de parâmetros: os $\lambda \mathrm{kj}$ l, referentes à probabilidade de que um indivíduo tipo puro de um perfil tenhaa probabilidade $(\lambda)$ de resposta (l) à variável(j), no perfil (k). Estas probabilidades valem apenas para indivíduos considerados "tipos puros" de um determinadoperfil, quais sejam: aqueles que possuempertencimento ao perfil igual a 1 , ou seja,gik=1,00. Assim, gik indica o pertencimento(g) do indivíduo (i) ao perfil (k). Esteparâmetro não possui interpretação probabilísticae pode ser interpretado como um atributo individual, e sua amplitude éde 0,00 a 1,00 (MANTON; WOODBURY;TOLLEY, 1994). 
Foram definidos 4 grupos no momento em que se gerou a análise dos dados, destes observei apenas os "tipos puros" com o intuito de gerar um panorama geral das características predominantes em cada um dos grupos e o que estas características podem trazer de informações. O primeiro grupo foram selecionados as observações nas quais o atributo predominante foi a integridade e neste grupo foram selecionados os fragmentos naturais e estilhas. O segundo grupo foram aslascas de quartzo branco, majoritariamente leitoso, corticais, proveniente de percussãounipolar e com presença de clivagens. Oterceiro grupo são de lascas de quartzo branco, leitoso, fragmento de lascamento, proveniente de percussão unipolar e com presença de clivagens. Finalmente o quarto grupo é composto por lascas de quartzo branco, leitoso, fragmento de lascamento, de percussão indeterminada e com presença de clivagens. 